\title{
Cell-based bioassay for compounds with prooxidant activity
}

\author{
M. Thomas \& L. Benov \\ Department of Biochemistry, Faculty of Medicine, \\ Kuwait University, Kuwait
}

\begin{abstract}
There is substantial evidence from epidemiological studies that the etiology of many 'modern' diseases is linked in part to environmental pollution. A number of observations suggest that an imbalance in cellular oxidants and antioxidants is a critical underlying factor. Many environmental pollutants, without being redoxactive and capable of causing oxidation in vitro, are able to shift the oxidant/antioxidant balance of the cells, thus triggering pathological responses. It is difficult to assess the biological impact of mixtures of environmental pollutants because of their complexity. We propose the parallel use of normal (parental) and genetically engineered superoxide dismutase (SOD)-deficient E. coli strains, as a tool for the detection of prooxidant-acting environmental pollutants. Doubling time, viability, mutation rate, and induction of antioxidant regulons are used as parameters to assess the pollutants' toxicity and prooxidant action. SOD-deficient $E$. coli is highly sensitive to agents causing oxidative stress directly or indirectly. This sensitivity can be measured and is highly reproducible. Using $E$. coli is advantageous because the organism is well studied, can be stored at low temperatures for a very long time, and can be grown under standard, well-defined conditions. The parallel use of SOD-deficient mutants and SOD-proficient parents permits discrimination between compounds that exert general toxicity and compounds that act as prooxidants in vivo. The bioassay was used for fast screening of potentially hazardous chemicals with pro-oxidative action.
\end{abstract}

Keywords: prooxidant, environmental pollutants, superoxide dismutasedeficient, oxidative stress, bioassay. 


\section{Introduction}

Increasing awareness that the environment is an important determinant of both individual and community health stimulates the search for a better understanding of the mechanisms of action of various environmental pollutants. There is substantial evidence from epidemiological studies that the etiology of a number of 'modern' diseases is linked in part to environmental pollution (Hennig et al. [1]). Many environmental contaminants, especially persistent organic pollutants, are risk factors for chronic diseases because they may exacerbate an underlying disease by altering gene expression patterns. Many mechanisms and signaling pathways associated with the pathology of 'modern' diseases are modulated by environmental pollutants. Pollutants have been found to contribute to the development of a wide range of diseases such as atherosclerosis (Hennig et al. [1], cancer (Brody et al. [2], Rumchev et al. [3]), diabetes (Yoshida et al. [4] Carpenter [5]), renal failure (Bertin and Averbeck [6]), cardiovascular (PrüssUstün et al. [7], Bjerregaard [8]), neurological (Grandjean and Landrigan [9]), and liver diseases (Yoshida et al. [4], Carpenter [5]), and can cause immunosuppression (Bertin and Averbeck [6]). Many genes induced in such diseases are oxidative stress-sensitive (Grandjean and Landrigan [9], Calabrese et al. [10], Watkins et al. [11]), suggesting that an imbalance in cellular redox status is a critical underlying factor (Hennig et al. [1]). Many environmental pollutants including heavy metals and various organic contaminants, without being redox active and prooxidative in vitro, are able to shift the oxidant/antioxidant balance of the cells, thus triggering pathological responses.

It is difficult to assess the biological impact of environmental pollutants acting as mixtures of individual compounds with different chemical properties and reactivities. More than 15,000 high volume production manmade chemicals are in use and hundreds more are introduced each year. More than half of them have never been tested for human toxicity (Landrigan et al. [12]), because the capacity to produce new chemicals exceeds the ability to test them (Chalupka [13]). This poses a demand for fast, easy and reliable methods for screening of potentially toxic chemicals. Whole-cell biosensors are finding increasing use in the detection of environmental pollution and toxicity (Ron [14]). Here we describe how the parallel use of normal (parental) and mutant, superoxide dismutase (SOD)-deficient strains (where the genes for the cytoplasmic SODs are deleted), can be used as a tool for the detection of prooxidant-acting environmental pollutants. We and others have demonstrated that the SODdeficient $E$. coli is highly sensitive to various agents contributing directly or indirectly to oxidative stress (Carlioz and Touati [15], Benov et al. $[16,17]$ ). Such sensitivity is manifested as retarded growth, increased mutation rates, induction of specific genes, and loss of viability. These responses can be easily measured and were found to be highly reproducible. Using E. coli as a biosensor is advantageous because the organism is well studied, can be stored at low temperatures for a very long time, and can be grown under standard, welldefined conditions. The parallel use of SOD-deficient mutants and SOD- 
proficient parents provides a basis for discrimination between compounds that exert general toxicity and compounds that act as prooxidants in vivo.

\section{Materials and methods}

\subsection{Strains}

The strains of E. coli used were: GC4468 = parental; QC1799 = GC4468 $\Delta$ sodA3 $\Delta$ sodB-kan Touati et al. [18]. These strains were prepared by D. Touati, Institute Jacques Monod, CNRS, University Paris, France. To ensure that the responses are not a consequence of the genetic background, the following strains were used in parallel : AB1157 = parental; JI132 = AB1157 plus (sodA:: MmdPR13) 25 (sodB-kan) 1- $\Delta 2$ Imlay et al. [19]; These strains were provided by J. Imlay, University of Illinois, Champaign-Urbana, Urbana, IL.

\subsection{Growth media}

Luria-Bertoni (LB) medium contained $10 \mathrm{~g}$ Bacto-tryptone, $5 \mathrm{~g}$ yeast extract, and $10 \mathrm{~g} \mathrm{NaCl}$ per liter and was adjusted to $\mathrm{pH} 7.0$ with $1.5 \mathrm{~g}$ of $\mathrm{K}_{2} \mathrm{HPO}_{4}$. M9CA medium consisted of minimal A salts ( $6 \mathrm{~g} \mathrm{Na}_{2} \mathrm{HPO}_{4}, 3 \mathrm{~g} \mathrm{~K}_{2} \mathrm{HPO}_{4}, 1 \mathrm{~g} \mathrm{NH} \mathrm{Nl}_{4}$, and $0.5 \mathrm{~g} \mathrm{NaCl}$ per liter (Maniatis et al. [20]); $\mathrm{MgSO}_{4}$ and $\mathrm{CaSO}_{4}$ were autoclaved separately and added to the cooled A salts to a final concentration of $20 \mathrm{mM}$ and $100 \mu \mathrm{M}$ respectively), $0.2 \%$ casamino acids, $0.2 \%$ glucose, $3 \mathrm{mg}$ pantothenate and $5 \mathrm{mg}$ of thiamine per liter. Minimal medium consisted of minimal A salts supplemented with $0.2 \%$ glucose.

Starter cultures were grown overnight at $37^{\circ} \mathrm{C}$, with shaking in air, in $\mathrm{LB}$ medium containing $50 \mu \mathrm{g} / \mathrm{ml}$ kanamycin and/or $30 \mu \mathrm{g} / \mathrm{ml}$ chloramphenicol where indicated. For monitoring growth, the overnight cultures were diluted 200 fold into M9CA medium not containing antibiotics. Freshly prepared filtersterilized solutions of chemicals to be tested were added and cultures were grown at $37^{\circ} \mathrm{C}$, with shaking in air. Respective controls not containing additives or containing solvents only were run in parallel. Growth was followed turbidimetrically at $600 \mathrm{~nm}$. For survival and MTT assays M9CA cultures were grown to $\mathrm{A}_{600 \mathrm{~nm}}=0.5-0.8$ and the cells were resuspended to the same density in minimal medium.

\subsection{MTT assay}

MTT (3-(4,5-dimethylthiazol-2-yl)-2,5-diphenyltetrazolium bromide) assay was performed using a modification of the original procedure of Mosmann [21]. Hundred $\mu \mathrm{l}$ aliquots of the cell suspensions were transferred into a 96-well plate, graded concentrations of the tested chemicals or progressively diluted samples were added and the plates were incubated for $1 \mathrm{~h}$ at $37^{\circ} \mathrm{C}$ on a shaker at $200 \mathrm{rpm}$. After the completion of the incubation $10 \mu \mathrm{l}$ of MTT reagent $(5 \mathrm{mg} / \mathrm{ml})$ were added to all wells and the plates were incubated for $30 \mathrm{~min}$ at $37^{\circ} \mathrm{C}$ on a shaker. After $30 \mathrm{~min}, 100 \mu \mathrm{l}$ of $10 \% \mathrm{SDS}$ in $10 \mathrm{mM} \mathrm{HCl}$ were added and plates were 
incubated for $1 \mathrm{~h}$ at room temperature. The solubilized product was assayed at $570 \mathrm{~nm}$, and the absorbance at $700 \mathrm{~nm}$ was used as a background value.

\subsection{Mutagenesis}

Mutagenesis was monitored by assaying the frequency of thymine-negative (Thy ${ }^{-}$) mutants. Thy mutants are resistant to the drug trimethoprim and can be selected from a $\mathrm{Thy}^{+}$population (Miller [22]). The assay was performed as described by Farr et al. [23]. For counting Thy mutants, aliquots of the cultures were plated directly on LB plates containing thymine $(50 \mu \mathrm{g} / \mathrm{ml})$ and trimethoprim $(15 \mu \mathrm{g} / \mathrm{ml})$. For enumeration of cells, cultures were suitably diluted and plated on LB plates containing thymine, but not trimethoprim.

Where indicated, exogenous metabolic activation was performed as described by Ames et al. [24] Hydrophobic organic compounds were dissolved in DMSO. All samples were tested at different concentrations in triplicate, both with and without microsomal activation. The S9 mixture contained the hepatic S9 fraction (1 $\mathrm{mg} / \mathrm{ml}$ of microsomal protein), and mid-log bacterial culture in M9CA medium.

All experiments were repeated 3-5 times with three replicates. Student t-test was used to determine statistical significance.

\section{Results and discussion}

E. coli contains three distinct SODs, CuZnSOD, FeSOD and MnSOD Touati [25]. Genes coding for MnSOD are designated as $\operatorname{sod} A$, for FeSOD $-\operatorname{sod} B$, and for CuZnSOD - sodC (Touati [26]). In E. coli both FeSOD and MnSOD are cytoplasmic, while the CuZnSOD is periplasmic (Benov et al. [27]). The sodA $\operatorname{sodB}$ strains are referred to as SOD-deficient even though they retain the periplasmic $\mathrm{CuZnSOD}$, which is expressed in stationary phase and is practically not present during exponential growth (Benov and Fridovich [28]).

The $\operatorname{sod} A \operatorname{sod} B$ mutants grow as well as the SOD-proficient parents anaerobically, but exhibit poor aerobic growth (Al-Maghrebi and Benov [29]), auxotrophy for certain amino acids (Benov et al. [30], Benov and Fridovich [31]), increased aerobic mutation rates (Farr et al. [23], Benov and Fridovich [32], and hypersensitivity to $\mathrm{H}_{2} \mathrm{O}_{2}$ and redox-cycling agents (Carlioz and Touati [15]).

The hypersensitivity of the SOD-deficient mutants to compounds causing oxidative stress suggested that those mutants could be used as sensors for potentially prooxidant environmental contaminants. To test this idea, parental and SOD mutants were subjected to treatment with various potentially toxic chemicals, including known prooxidants, and physiological responses such as changes in growth rate, decrease in viability, acceleration of mutation rate, and overall changes in metabolic rate were determined. 


\subsection{Effect of toxic compounds on $E$. coli growth and viability}

Growth of parental and SOD-deficient strains was followed in the presence of chemicals with prooxidant activity and compared to the growth with chemicals which are known to be toxic, but without known prooxidant activity. Fig. $1 \mathrm{~A}$ shows growth curves of SOD-proficient and SOD-deficient cultures and the effect of $\mathrm{Cd}^{2+}$. The effect of graded concentrations of $\mathrm{CdCl}_{2}$ on the growth of parental and mutant cultures is shown in fig. $1 \mathrm{~B}$.
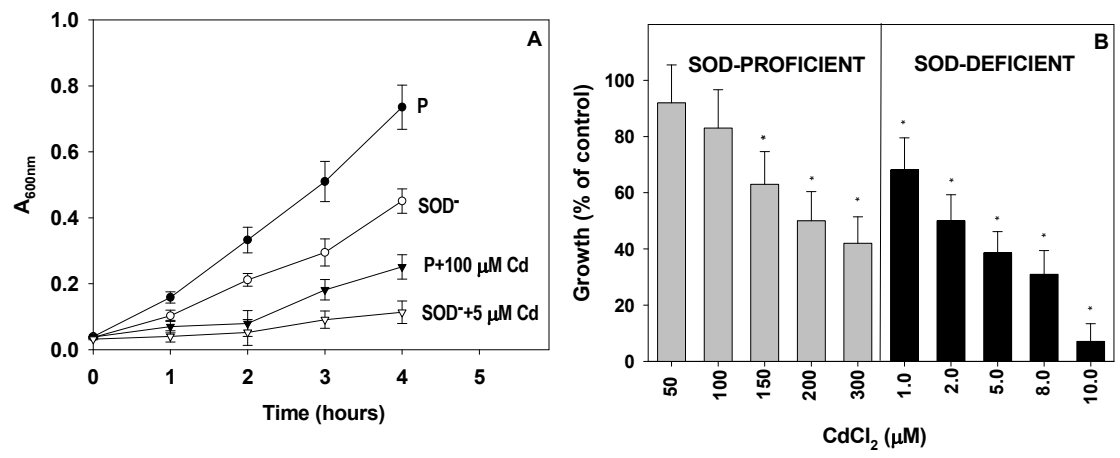

Figure 1: Effect of $\mathrm{CdCl}_{2}$ on proliferation of SOD-proficient and SODdeficient strains in M9CA medium. Panel A, growth curves; Panel $\mathrm{B}$, growth rates. Growth was monitored as absorbance at $600 \mathrm{~nm}$. The growth rate of control cultures (without toxic additions) was calculated as $100 \%$. Values significantly different from control $(\mathrm{p}<0.05)$ are indicated with a $(*)$. Values are means of triplicates \pm $\mathrm{SE}$ and are representative of at least three independent experiments.

Fig. 2 illustrates the higher sensitivity of the SOD-deficient mutants to some heavy metals ( $\mathrm{Hg}, \mathrm{Cd}$ ), paraquat (methyl viologen), phenazine methosulfate (PMS), peroxides, short-chain sugars, dicarbonyls, and even to ascorbate, which is considered an antioxidant.

No differences between parental and $\operatorname{sodAsodB}$ mutants were observed with respect to sensitivity towards pyridine (fig. 2 A), and similar effect was observed for arsenate, dimethylamine, formaldehyde, and chlorhexidine digluconate (not shown). Other compounds, considered potentially toxic (acrylamide, nitrate) had no effect at the tested concentrations.

The hypersensitivity of the $\operatorname{sodAsodB}$ cells towards heavy metals such as $\mathrm{Cd}$ and $\mathrm{Hg}$ has its explanation. Even though those metals are not redox active and cannot act as prooxidants in vitro, in vivo $\mathrm{Cd}$ was shown to increase the production of superoxide by interfering with the respiratory electron transport chain (Belyaeva et al. [33], Wang et al. [34]), while Hg being a sufhydryl poison was shown to indirectly increase ROS production (Kovacic and Somanathan [35]) and to induce the $\mathrm{O}_{2}^{--}$-sensing soxRS regulon in E. coli (Fuentes and Amábile-Cuevas [36]). The prooxidant effect of otherwise considered antioxidants, for example ascorbate and cysteine, can be explained by coupled 
redox-cycling with transition metals (Park and Imlay [37]), and that of paraquat and PMS, to intracellular redox-cycling, producing superoxide (Hassan and Fridovich [38]). Fig. 2 demonstrates that compared to the SOD-proficient parent, less $\operatorname{sod} A \operatorname{sod} B$ cells survived in the presence of common metabolites such as triose-phosphates. The reason lies in $\mathrm{O}_{2}^{-}$-dependent oxidation to $\alpha, \beta$ dicarbonyl compounds (Benov et al. [16], Benov and Fridovich [17]), and their lower rate of elimination by the SOD-deficient cells (Okado-Matsumoto and Fridovich [39]).
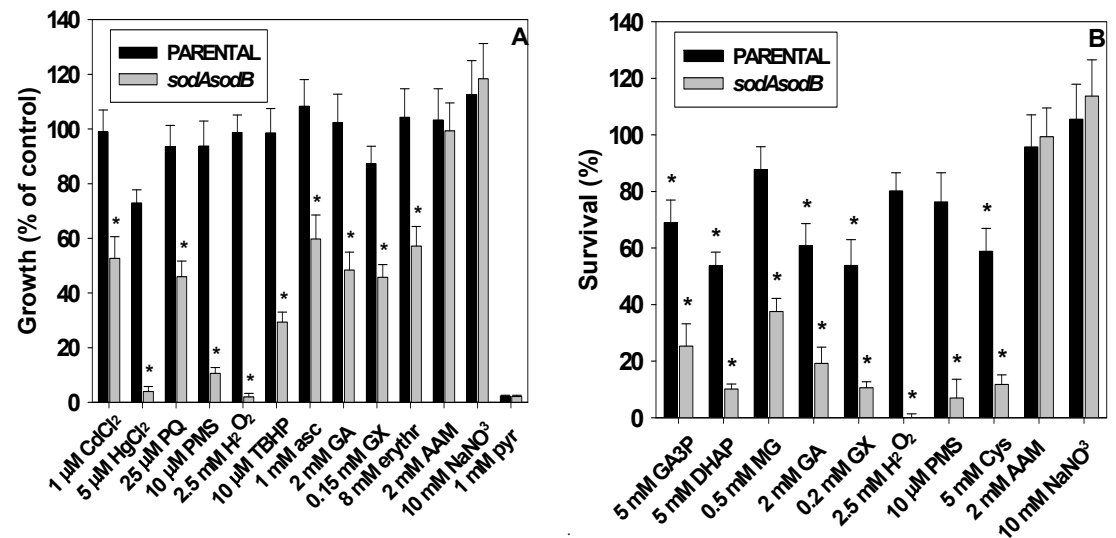

Figure 2: $\quad$ Effect of toxic compounds on growth (Panel A) and viability (Panel B) of parental and $\operatorname{sod} A \operatorname{sodB}$ strains. To compensate for the volume added by the tested sample, an equal volume of the carrier was added to control cultures. Values significantly different from control $(\mathrm{p}<0.05)$ are indicated with a $(*)$. Means of triplicates $\pm \mathrm{SE}$ are shown and are representative of at least three independent experiments. PQ - paraquat; PMS - phenazine methosulfate; TBHP - tert-Butyl hydroperoxide; Asc - sodium ascorbate; GA glycolaldehyde; GX - glyoxal; Erythr - erythrose; AAM acrylamide; Pyr - pyridine; GA3P - glyceraldehyde-3-phosphate; DHAP - dihydroxyacetone phosphate; MG - methylglyoxal; Cys cysteine.

\subsection{MTT reduction test}

Results shown above demonstrate that $E$. coli growth rate and viability can be used as relatively easily measurable parameters for assessment of toxicity and prooxidant effect. Growth, however, needs to be followed for relatively long time intervals and viability assessment requires plating and enumeration of colonies, which is time- and work-demanding. Methods based on reduction of tetrazolium salts to purplish-blue formazan products have become some of the most widely used tools for assessing cell viability and proliferation in cell biology. Since production of colored formazan depends on cell metabolism 
(Berridge et al. [40]), the assay has been widely used for measuring the metabolic activity of cells ranging from mammalian to microbial. It has been proved suitable for assessing microbial cell proliferation (Tsukatani et al. [41]) and viability (Tsukatani et al. [42]), as well as bactericidal activity (Stevens et al. [43], Stevens and Olsen [44]). A comparison between the effects of prooxidant and non-prooxidant toxic compounds on cell proliferation and viability with MTT test, performed in a 96-well plate, demonstrated that MTT reduction can be used as a method for fast initial screening of a big number of samples (fig. 3 ).

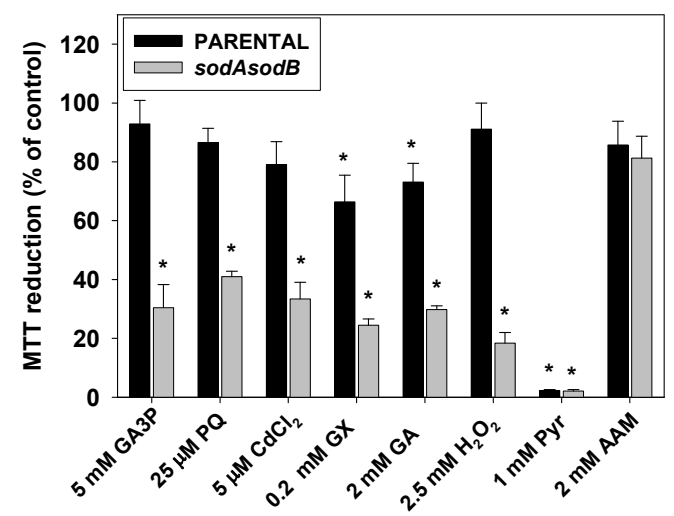

Figure 3: $\quad$ MTT reduction test. GA3P - glyderaldehyde-3-phosphate; PQ paraquat; GX - glyoxal; GA - glycolaladehyde; Pyr - pyridine; AAM - acrylamide.

\subsection{Mutagenesis}

It is known that in aerobic environment, the $\operatorname{sodAsodB} E$. coli cells mutate faster than the parental cells, which has been attributed to ROS-mediated DNA damage. This finding implies that compounds, which increase ROS production, i.e. act as prooxidants either directly or indirectly, would eventually further increase mutation rates, and SOD-deficient cells would be more sensitive. This is illustrated by the bigger number of mutants in SOD-deficient cultures treated with short-chain aldehydes (fig. 4).

Activation by rat hepatic S9 fraction, as described in the Ames' mutagenicity test, has been found to suppress the mutagenic effect of short-chain aldehydes, but potentiated the mutagenic effect of known mutagens such as benzpyrene (not shown). The assay was tested with samples of sea water, collected from different parts of Kuwait's coastal area. Fig. 5 shows increased mutagenicity of the SOD-deficient cells by S9-activated seawater samples (SW2 and SW3) collected from areas polluted as a result of a spill of sewage water from a malfunctioning sewage-treatment plant. 


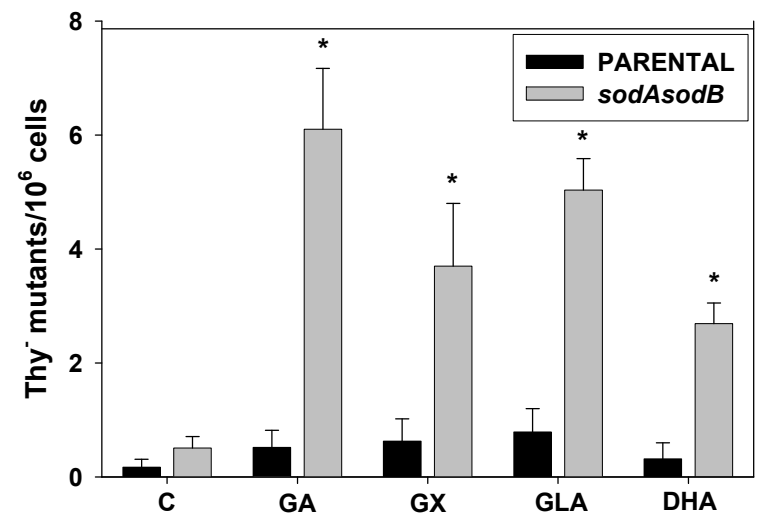

Figure 4: Prooxidant-acting compounds are much stronger mutagens for the SOD-deficient than for the parental strain. Overnight LB cultures of SOD-proficient and SOD-deficient strains were diluted 200 fold in M9CA medium and were grown aerobically at $37^{\circ} \mathrm{C}$ and $200 \mathrm{rpm}$ to a density of $\mathrm{A}_{600 \mathrm{~nm}} \sim 0.5$. At this point compounds to be tested were added and the cells were kept for $2 \mathrm{~h}$ on the shaker. After the incubation, the cells were diluted and plated on LB plates containing thymine for assessing cell number or aliquots were plated without dilution on LB plates containing thymine and trimethoprim for counting Thy mutants. Bars represent mean \pm S.E.M. (n=3).GA - glycolaldehyde; GX - glyoxal; GLA glyceraldehyde; DHA - dihydroxyacetone.

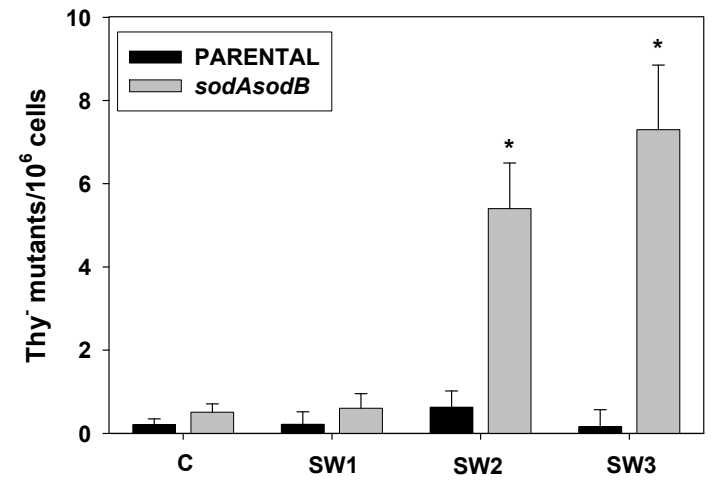

Figure 5: Mutagenicity of seawater samples collected from areas polluted with raw sewage (SW2 and SW3). Non-polluted seawater (SW1) was tested for comparison. Mutagenicity test was performed after activation by rat hepatic S9 fraction. 


\section{Conclusions}

In conclusion, the data presented here indicate that the parallel use of SODproficient and SOD-deficient $E$. coli strains is a promising cell-based system for detection of environmental pollutants with potentially prooxidant action. Detailed studies with a bigger number of chemicals will be needed in order to assess the practical usefulness and the limitations of the proposed biosensor.

\section{Acknowledgements}

This work was supported by Kuwait University grants MB 03/07 and Research Core Facility grants GM01/01 and GM01/05.

\section{References}

[1] Hennig, B., Oesterling, E. \& Toborek, M., Environmental toxicity, nutrition, and gene interactions in the development of atherosclerosis. Nutrition Metabolism \& Cardiovascular Diseases, 17, pp. 162-169, 2007.

[2] Brody, J.G., Rudel, R.A., Michels, K.B., Moysich, K.B., Bernstein, L., Attfield, K.R. \& Gray, S., Environmental pollutants, diet, physical activity, body size, and breast cancer: where do we stand in research to identify opportunities for prevention? Cancer, 109, pp. 2627-2634, 2007.

[3] Rumchev, K., Brown, H. \& Spickett, J., Volatile organic compounds: do they present a risk to our health? Reviews on Environmental Health, 22, pp. 39-55, 2007.

[4] Yoshida, T., Yamauchi, H. \& Fan Sun, G., Chronic health effects in people exposed to arsenic via the drinking water: dose-response relationships in review. Toxicology \& Applied Pharmacology, 198, pp. 243-52, 2004.

[5] Carpenter, D.O., Polychlorinated biphenyls (PCBs): routes of exposure and effects on human health. Reviews on Environmental Health, 21, pp. 1-23, 2006.

[6] Bertin, G. \& Averbeck, D., Cadmium: cellular effects, modifications of biomolecules, modulation of DNA repair and genotoxic consequences (a review). Biochimie, 88, pp. 1549-1559, 2006.

[7] Prüss-Ustün, A., Vickers, C., Haefliger, P. \& Bertollini, R., Knowns and unknowns on burden of disease due to chemicals: A systematic review. Environmental Health: A Global Access Science Source, 10, pp. 1-15, art. no. 9, 2011.

[8] Bjerregaard, P., Cardiovascular disease and environmental pollutants: the Arctic aspect. Arctic Medical Research, 1, pp. 25-31, 1996.

[9] Grandjean, P. \& Landrigan, P.J., Developmental neurotoxicity of industrial chemicals. Lancet, 368, pp. 2167-2178, 2006.

[10] Calabrese, V., Guagliano, E., Sapienza, M., Mancuso, C., Butterfield, D.A. \& Stella, A.M., Redox regulation of cellular stress response in neurodegenerative disorders. Italian Journal of Biochemistry, 55, pp. 263282, 2006. 
[11] Watkins, B.A., Hannon, K., Ferruzzi, M. \& Li, Y., Dietary PUFA and flavonoids as deterrents for environmental pollutants. Journal of Nutritional Biochemistry, 18, pp. 196-205, 2007.

[12] Landrigan, P.J., Carlson, J.E., Bearer, C.F., Cranmer, J.S., Bullard, R.D., Etzel, R.A., Groopman, J., McLachlan, J.A., Perera, F.P., Reigart, J.R., Robison, L., Schell, L. \& Suk, W.A., Children's health and the environment: a new agenda for prevention research. Environmental Health Perspectives, 3, pp. 787-794, 1998.

[13] Chalupka, S.M., Essentials of environmental health. Enhancing your occupational health nursing practice (Part I). AAOHN Journal, 49, pp. 137 153, 2001.

[14] Ron, E.Z., Biosensing environmental pollution. Current Opinion in Biotechnology, 18, pp. 252-256, 2007.

[15] Carlioz, A. \& Touati, D., Isolation of superoxide dismutase mutants in Escherichia coli is superoxide dismutase necessary for aerobic life? EMBO Journal, 5, pp. 623-630, 1986.

[16] Benov, L., Beema, A.F. \& Sequeira, F., Triosephosphates are toxic to superoxide dismutase-deficient Escherichia coli. Biochimica et Biophysica Acta, 1622, pp. 128-132, 2003.

[17] Benov, L. \& Fridovich, I., Superoxide dependence of the toxicity of short chain sugars. Journal of Biological Chemistry, 273, pp. 25741-25744, 1998.

[18] Touati, D., Jacques, M., Tardat, B., Bouchard, L. \& Despied, S., Lethal oxidative damage and mutagenesis are generated by iron in $\Delta$ fur mutants of Escherichia coli: Protective role of superoxide dismutase. Journal of Bacteriology, 177, pp. 2305-2314, 1995.

[19] Imlay, J.A. \& Fridovich, I., Isolation and genetic analysis of a mutation that suppresses the auxotrophies of superoxide dismutase-deficient Escherichia coli K12. Molecular and General Genetics, 228, pp. 410-416, 1991.

[20] Maniatis, T., Fritsch, E.F. \& Sambrook, J., Molecular Cloning: A Laboratory Manual, Cold Spring Harbor Laboratory, Cold Spring Harbor, NY, 1982.

[21] Mosmann, T., Rapid colorimetric assay for cellular growth and survival: Application to proliferation and cytotoxicity assays. Journal of Immunological Methods, 65, pp. 55-63, 1983.

[22] Miller, J.H., Experiments in molecular genetics, Cold Spring Harbor Laboratory 1972.

[23] Farr, S.B., D'Ari, R. \& Touati, D., Oxygen-dependent mutagenesis in Escherichia coli lacking superoxide dismutase. Proceedings of the National Academy of Sciences of the United States of America, 83, pp. 8268-8272, 1986.

[24] Ames, B.N., McCann, J. \& Yamasaki, E., Methods for detecting carcinogens and mutagens with the Salmonella mammalian-microsome mutagenicity test. Mutation Research, 31, pp. 347-364, 1975.

[25] Touati, D., Molecular genetics of superoxide dismutases. Free Radical Biology and Medicine, 5, pp. 393-402, 1988. 
[26] Touati, D., The molecular genetics of superoxide dismutase in E. Coli. An approach to understanding the biological role and regulation of sods in relation to other elements of the defence system against oxygen toxicity. Free Radical Research Communications, 8, pp. 1-9, 1989.

[27] Benov, L., Chang, L.Y., Day, B. \& Fridovich, I., Copper, zinc superoxide dismutase in Escherichia coli periplasmic localization. Archives of Biochemistry and Biophysics, 319, pp. 508-511, 1995.

[28] Benov, L.T. \& Fridovich, I., Escherichia coli expresses a copper- and zinccontaining superoxide dismutase. Journal of Biological Chemistry, 269, pp. 25310-25314, 1994.

[29] Al-Maghrebi, M.A. \& Benov, L.T., Polyphosphate accumulation and oxidative DNA damage in superoxide dismutase-deficient Escherichia coli. Free Radical Biology and Medicine, 31, pp. 1352-1359, 2001.

[30] Benov, L., Kredich, N.M. \& Fridovich, I., The mechanism of the auxotrophy for sulfur-containing amino acids imposed upon Escherichia coli by superoxide. Journal of Biological Chemistry, 271, pp. 21037 21040, 1996.

[31] Benov, L. \& Fridovich, I., Why superoxide imposes an aromatic amino acid auxotrophy on Escherichia coli: The transketolase connection. Journal of Biological Chemistry, 274, pp. 4202-4206, 1999.

[32] Benov, L. \& Fridovich, I., The rate of adaptive mutagenesis in Escherichia coli is enhanced by oxygen (superoxide). Mutation Research, 357, pp. 231236, 1996.

[33] Belyaeva, E.A., Dymkowska, D., Wieckowski, M.R. \& Wojtczak, L., Reactive oxygen species produced by the mitochondrial respiratory chain are involved in $\mathrm{Cd} 2+$-induced injury of rat ascites hepatoma AS-30D cells. Biochimica et Biophysica Acta - Bioenergetics, 1757, pp. 1568-1574, 2006.

[34] Wang, Y., Fang, J., Leonard, S.S. \& Rao, K.M.K., Cadmium inhibits the electron transfer chain and induces reactive oxygen species. Free Radical Biology and Medicine, 36, pp. 1434-1443, 2004.

[35] Kovacic, P. \& Somanathan, R., Unifying mechanism for metals in toxicity, carcinogenicity and therapeutic action: Integrated approach involving electron transfer, oxidative stress, antioxidants, cell signaling and receptors. Journal of Receptors and Signal Transduction, 30, pp. 51-60, 2010.

[36] Fuentes, A.M. \& Amábile-Cuevas, C.F., Mercury induces multiple antibiotic resistance in Escherichia coli through activation of SoxR, a redox-sensing regulatory protein. FEMS Microbiology Letters, 154, pp. 385-388, 1997.

[37] Park, S. \& Imlay, J.A., High levels of intracellular cysteine promote oxidative DNA damage by driving the Fenton reaction. Journal of Bacteriology, 185, pp. 1942-1950, 2003.

[38] Hassan, H.M. \& Fridovich, I., Intracellular production of superoxide radical and of hydrogen peroxide by redox active compounds. Archives of Biochemistry and Biophysics, 196, pp. 385-395, 1979. 
[39] Okado-Matsumoto, A. \& Fridovich, I., The role of $\alpha, \beta$-dicarbonyl compounds in the toxicity of short chain sugars. Journal of Biological Chemistry, 275, pp. 34853-34857, 2000.

[40] Berridge, M.V., Herst, P.M. \& Tan, A.S., Tetrazolium dyes as tools in cell biology: New insights into their cellular reduction. Biotechnology Annual Review 11 (SUPPL.), pp. 127-152, 2005.

[41] Tsukatani, T., Suenaga, H., Higuchi, T., Akao, T., Ishiyama, M., Ezoe, K. \& Matsumoto, K., Colorimetric cell proliferation assay for microorganisms in microtiter plate using water-soluble tetrazolium salts. Journal of Microbiological Methods, 75, pp. 109-116, 2008.

[42] Tsukatani, T., Higuchi, T., Suenaga, H., Akao, T., Ishiyama, M., Ezoe, T. \& Matsumoto, K., Colorimetric microbial viability assay based on reduction of water-soluble tetrazolium salts for antimicrobial susceptibility testing and screening of antimicrobial substances. Analytical Biochemistry, 393, pp. 117-125, 2009.

[43] Stevens, M.G., Kehrli Jr, M.E. \& Canning, P.C., A colorimetric assay for quantitating bovine neutrophil bactericidal activity. Veterinary Immunology and Immunopathology, 28, pp. 45-56, 1991.

[44] Stevens, M.G. \& Olsen, S.C., Comparative analysis of using MTT and XTT in colorimetric assays for quantitating bovine neutrophil bactericidal activity. Journal of Immunological Methods, 157, pp. 225-231, 1993. 